\title{
RESPONSABILIZAÇÃO, MERITOCRACIA E DESFILIAÇÃO SOCIAL NO BRASIL ${ }^{1}$
}

\author{
ACCOUNTABILITY, MERITOCRACY AND SOCIAL DISTILLATION IN BRAZIL
} RESPONSABILIDAD, MERITOCRACIA Y DESFILIACIÓN SOCIAL EN BRASIL

Audrei Rodrigo da Conceição Pizolati Mestre e doutorando em Educação pela Universidade do Vale do Rio dos Sinos - UNISINOS. São Leopoldo, Rio Grande do Sul, Brasil. audreipizolati@gmail.com

\author{
Alexandre Alves \\ Doutor em História pela Universidade de São Paulo - USP. \\ Pós-doutorado no Programa de Pós-graduação em Educação da Universidade do Vale do Rio dos Sinos - UNISINOS \\ São Leopoldo, Rio Grande do Sul, Brasil \\ sandoralves@gmail.com
}

Resumo: O artigo investiga as razões para a mudança de ênfase nas propostas pedagógicas brasileiras em dois momentos históricos: entre os anos 1920 e 1930 e entre os anos 1990 e 2010. Com esse objetivo em vista, procede-se à análise de fontes como a I Conferência Nacional de Educação (1927), o Manifesto dos Pioneiros (1932) e, para o período contemporâneo, leis e decretos nacionais (1996-2018). No primeiro contexto, foi possível verificar que o debate entre os saberes biológicos e os sociológicos em busca de legitimação encontra na área de educação seu principal palco de disputa. No passado, intelectuais influenciados pela eugenia recorreram à biologia como forma de modernizar o país por meio da educação eugênica e da exclusão dos indivíduos "indesejados". Nas últimas décadas, observa-se um retorno desse tipo de discurso de fundo biológico, mas agora a exclusão biossocial de sujeitos apela não mais à ideologia da nação, mas à sacralização neoliberal da "meritocracia". Da comparação entre os dois contextos, conclui-se que a mudança de ênfase nas propostas pedagógicas que antes primavam pelo social, agora visa a formação individualizante do "neossujeito" flexível e responsável por si mesmo. O sucesso e insucesso escolar passam a ser vistos unicamente como dependentes da capacidade do indivíduo de gerenciar sua própria vida e não como resultado de problemas estruturais da sociedade, o que tem conduzido a um processo de crescente desfiliação social.

Palavras-chave: desfiliação social; meritocracia; políticas de responsabilização.

Abstract: This paper investigates the reasons for the change of emphasis in Brazilian pedagogical proposals in two historical moments: between the 1920s and 1930s and between the 1990s and 2010. With this aim in mind, sources such as the 1st National Conference on Education (1927), the Pioneers Manifesto (1932) and, for the contemporary period, national laws and decrees (1996-2018) are analyzed. In the first context, it was possible to verify that the debate between biological and sociological knowledge in search of legitimacy finds its main stage of dispute in the area of education. In the past, intellectuals influenced by eugenics turned to biology as a way to modernize the country through eugenic education and the exclusion of "unwanted" individuals. In recent decades, there has been a return of this type of discourse with a biological basis, but now the biosocial exclusion of subjects no longer appeals to the nation's ideology, but to the neoliberal sacralization of "meritocracy". From the comparison between the two contexts, it can be concluded that the change of emphasis in the pedagogical proposals that once stood out for the social, now aims at the individualizing training of the flexible and self-responsible "neo-subject". School success and failure are seen as dependent only on the individual's ability to manage her or his own life and not as a result of structural problems in society, which has led to an increasing process of social disaffiliation.

Keywords: social disaffiliation; meritocracy; responsibility policies.

Resumen: El artículo investiga las razones del cambio de énfasis en las propuestas pedagógicas brasileñas en dos momentos históricos: entre las décadas de 1920 y 1930 y entre las décadas de 1990 y 2010. Con este objetivo en mente, se analizan fuentes como el I Congreso Nacional de Educación (1927), el Manifiesto de los Pioneros (1932) y, para la época contemporánea, las leyes y decretos nacionales (1996-2018). En el primer contexto, se pudo constatar que el debate entre saberes biológicos y sociológicos en busca de legitimidad encuentra su principal escenario de disputa en el área de la educación. En el pasado, los intelectuales influenciados por la eugenesia recurrieron a la biología como una forma de modernizar el país a través de la educación eugenésica y la exclusión de individuos "no deseados". En las últimas décadas se ha producido un retorno de este tipo de discurso con base biológica, pero ahora la exclusión biosocial de los sujetos ya no apela a la ideología de la nación, sino a la sacralización neoliberal de la "meritocracia". De la comparación entre los dos contextos se puede concluir que el cambio de énfasis en las propuestas pedagógicas que antes destacaban por lo social, ahora apunta a la formación individualizadora del "neo-sujeto" flexible y autorresponsable. El éxito y el fracaso escolar se consideran ahora únicamente como dependientes de la capacidad del individuo para manejar su propia vida y no como resultado de problemas estructurales en la sociedad, lo que ha llevado a un proceso de creciente desafiliación social.

Palabras clave: desafiliación social; meritocracia; políticas de rendición de cuentas.

Para citar - (ABNT NBR 6023:2018)

PIZOLATI, Audrei Rodrigo da Conceição; ALVES, Alexandre. Responsabilização, meritocracia e desfiliação social no Brasil. Eccos - Revista Científica, São Paulo, n. 58, p. 1-19, e11137, jul./set. 2021. Disponível em: https://doi.org/10.5585/eccos.n58.11137.

\footnotetext{
${ }^{1}$ Essa pesquisa contou com o apoio da Coordenação de Aperfeiçoamento de Pessoal de Nível Superior - Brasil (CAPES). Agradecemos igualmente ao Grupo
} Interinstitucional de Pesquisa em Docências, Pedagogias e Diferenças (GIPEDI - UNISINOS/CNPq). 


\section{Introdução}

O objetivo deste artigo é investigar a mudança de ênfase nas propostas pedagógicas brasileiras entre as primeiras décadas do séc. XX e o início do séc. XXI que visam a constituição de um "neossujeito" flexível, competitivo e responsável por si mesmo, o que decorre da atualização dos discursos biológicos e sociológicos que influenciam a produção de políticas públicas educacionais no presente. Para tanto, levou-se em consideração as políticas sociais afirmativas brasileiras criadas no período que compreende os anos de 1996 e 2018. Esse recorte se dá devido ao fato de que no governo Fernando Henrique Cardoso se intensificaram as políticas neoliberais no país. Sobre a delimitação do passado, considera-se ser suficiente a investigação daquele período no intuito de demonstrar como a formação do indivíduo estava voltada para o seu advento na sociedade. Foi no contexto das primeiras décadas do século XX que se debateu e se pensou a escola nacional e a educação do brasileiro novecentista. A educabilidade desses sujeitos que antes primava pelo social é reconfigurada após o ano de 1996 - advento da Lei de Diretrizes e Bases para a Educação Nacional (LDBEN) -, privilegiando uma formação individualizada e individualizante.

O primeiro movimento estabelecido na pesquisa foi o de analisar como o saber eugênico no início do século XX se vinculou aos saberes biológicos, médicos e higienistas no intuito de ganhar cientificidade frente às teorias sociais. A esse processo, Vanderlei Souza (2006) atribui a facilidade de assimilação do discurso eugênico - que tinha em seu rol de entusiastas pedagogos, juristas, literatos e médicos entre outros - por diferentes correntes teóricas devido ao seu "caráter polimorfo". Aliás, é importante destacar que a eugenia não se restringiu a nenhuma corrente política e ideológica específicas. Sendo essa teoria apreciada por liberais, comunistas e anarquistas, o que estava em pauta à época foi a melhoria do corpo social por meio do cruzamento entre os melhores espécimes humanos (STEPAN, 2005). Quanto à crescente influência eugênica na Europa e nos Estados Unidos, o médico brasileiro Alexandre Tepedino se posicionou com certo entusiasmo: "Há agora uma sciencia nova, que floresce entre anglo-saxônicos da Europa e da América, e que se intitula a Eugenia ou o estudo da boa procriação da nobreza dos seres humanos." (TEPEDINO, 1914, p. 03).

A eugenia objetivava o aprimoramento da espécie humana por intermédio da união entre seres eugenizados que seriam supostamente dotados de melhores características físicas, cognitivas e morais que seus semelhantes. Com isso, eliminar-se-iam os riscos biológicos inatos e/ou adquiridos presentes em sujeitos considerados disgênicos, "degenerados" e "inaptos" físicos, cognitivos e ou morais (PIZOLATI; ALVES, 2019). 
No Brasil, além desse objetivo, a eugenia caracterizou-se pela participação da burguesia e das classes médias urbanas alinhadas com o imaginário cientificista da época. Na contramão da interpretação de Nancy Stepan, Hobsbawn afirmou que a eugenia era também um “[...] movimento político, em sua esmagadora maioria composto de membros de classe média e burguesa, que pressionavam os governos para que implantassem programas de ações positivas ou negativas visando melhorar a condição genética da espécie humana." (HOBSBAWM, 2001, p. 350). Vale a pena destacar que, apesar de não estar restrito a uma ideologia política específica, o conceito de eugenia não é neutro, permitindo articular-se a distintas correntes de opinião que resultam, nos dias atuais, no "fascismo social" dos movimentos neoconservadores. (ALVES; PIZOLATI, 2019).

Este debate que envolveu o aprimoramento da "raça" sofreu resistências por parte de antropólogos como Fróes da Fonseca e Edgar Roquette-Pinto, que se opuseram à eugenia radical. Havia um embate entre o determinismo biológico e o sociológico sobre a constituição do indivíduo. Isso reverberou na formação do imaginário social que hipoteticamente entende algumas pessoas como sendo "menos humanas" e, portanto, menos dignas de proteção social ou de direitos. O professor Boaventura Santos (2010, p. 192) evidencia a questão da cidadania por intermédio do conceito de fascismo social, em que "[...] um conjunto de processos sociais mediante os quais grandes setores da população são irreversivelmente mantidos no exterior ou expulsos de qualquer tipo de contrato social."

Se no passado o fator de insucesso estaria condicionado aos fatores biológicos, na atualidade, o discurso neoliberal busca na sociobiologia o fundamento necessário para promover o ideal de competitividade. Uma vez que seríamos heterogêneos sob o ponto de vista da biologia, ao Estado caberia apenas garantir as condições mínimas necessárias para o desenvolvimento da autonomia e para a geração de renda entre os indivíduos, tornando-os autônomos e responsáveis. Com isso, há uma mudança de ênfase que agora é deslocada para a sobrevivência do espécime - do eu -, algo que é potencializado pelo neoliberalismo, configurando o gradual deslocamento do individual para o hiperindividualismo.

No prosseguimento deste artigo, apresentam-se as ferramentas teórico-metodológicas utilizadas na análise da materialidade escolhida. Na seção que se sucede, problematiza-se como na década de 1920 o determinismo biológico foi debatido pelos antropólogos e educadores da época. Por fim, investiga-se como políticas afirmativas propostas pelo Estado brasileiro fomentam uma racionalidade neoliberal que visa à instituição de sujeitos autônomos, geradores de renda e empresários de si mesmos. 


\section{Aporte teórico-metodológico}

Com base na analítica do poder de Michel Foucault, para o manuseio do objeto analítico, operou-se com os conceitos de discurso, biopolítica, regime de verdade e governo de si. Os dispositivos biopolíticos são entendidos, de maneira geral, como um conjunto de práticas disciplinares que tem por objetivo governar a conduta dos indivíduos (FOUCAULT, 2013). Neste caso, a condução estaria tencionada entre o saber biológico e o social, não trazendo em si um sentido de rompimento, mas de uma fusão destes saberes - daí podermos falar em "sociobiologia". Por esse motivo, lança-se mão também do conceito de governo de si, na medida em que a própria conduta do indivíduo está implicada nas técnicas biopolítica de governo (FOUCAULT, 2012). Os "[...] discursos sobre a verdade, sobre os 'regimes de verdade' que instruem e firmam os parâmetros de governamento dos sujeitos, de sua normalidade e de sua anormalidade [...]" (SILVA, 2014, p. 901) pautam os modos como o indivíduo se constitui e se percebe no mundo.

Esses debates referentes a formação do indivíduo no início do século passado foram permeados por discursos biológicos e sociais. Para tanto, como materialidade investigativa recorreu-se à I Conferência Nacional de Educação (I CNE) e ao Manifesto dos Pioneiros por se tratar de documentos que nortearam as propostas pedagógicas brasileiras novecentistas. Ademais, outros estudos de época que versavam sobre o tema em pauta e que envolviam a eugenia e a educação também foram incluídos nas análises.

Isto posto, antes de adentrar às análises do contexto político atual, fez-se necessário investigar como no início do séc. XX foram pensadas as políticas de educação voltadas para o trabalho e para o desenvolvimento da sociedade. Assim, demarca-se a mudança de ênfase que antes privilegiava o bem-comum acima dos interesses individuais e, atualmente, através da educação meritocrática pensada em chave neoliberal, a ênfase recai no fomento à individualidade exacerbada - noutras palavras: o hiperindividualismo contemporâneo cada vez mais enaltece o $e u$ e se sobrepõe ao social.

\section{Educação, trabalho e sociedade nas primeiras décadas do século XX}

Na década de 1920, inúmeras reformas pedagógicas foram instituídas nos principais estados da federação. No Nordeste, houve as reformas Lourenço Filho no Ceará (1923) e Anísio Teixeira na Bahia (1923). Sampaio Dória foi o responsável pela reestruturação do ensino paulista em 1920. Francisco Campos assumiu a educação em Minas Gerais (1927) e Fernando de Azevedo no Distrito Federal - Rio de Janeiro à época - (1928). Esses intelectuais 
supracitados foram considerados os principais reformadores educacionais no país naquele período. É importante destacar que o risco de desordem política e social com a crescente agitação operária, sob a influência do anarco-sindicalismo, a imigração e a urbanização acelerada das cidades exigiram das autoridades o estabelecimento de um ensino que visasse o disciplinamento dos jovens, forjando-os para a ordem, a família e o trabalho. Além de problemas sanitários e de higiene da época, o analfabetismo seria outro entrave para o desenvolvimento nacional. Para os liberais, somente através da qualificação da população, mediante o acesso à educação, é que o Estado brasileiro resolveria esses problemas e alcançaria o progresso.

No tocante a Azevedo, Campos e Teixeira, eles estabeleceram uma crítica ao modelo tradicional de ensino, pois para eles a educação deveria estar voltada para a modernidade, o progresso e o desenvolvimento científico. Referente à reforma de Dória em São Paulo, em que o ensino estava voltado para formar as grandes massas para o trabalho, Teixeira (1925) reconhecia a inovação pedagógica neste processo, uma vez que este modelo promoveria a difusão da educação entre as classes sociais menos favorecidas.

Nesse sentido, a formação do indivíduo obedeceria a critérios liberais, confluindo com a perspectiva fordista, conforme disposta na I CNE, a saber:

Toda verdadeira Pedagogia tenderá para o ensino da Economia, no tempo e no espaço. Tudo no melhor processo, com o mínimo de dispêndio e o máximo de proveito, na maior velocidade.

Toda Pedagogia moderna será fordiana: irá buscar nos livros de Ford os processos da vitória, com o máximo de humanidade, no mais intenso sistema de economia, com a generalidade das especializações. Para o fordismo não há aleijados, não há inúteis; todos cooperam para a obra geral. (XAVIER, 1927 In: COSTA; SHENA; SHIMIDT, 1997, p. 71).

Para o desenvolvimento do fordismo no país, primeiramente seria necessário resolver os problemas sanitários que acometiam a nação. O cenário da época era preocupante, fazendo com que as autoridades políticas e intelectuais se unissem diante do enfrentamento desses problemas endêmicos que estavam relacionados às péssimas condições de higiene no país. Para o sanitarista e eugenista Belisário Penna, essa situação calamitosa seria reflexo da baixa instrução escolar, que não propiciaria um governo de si em linha com o ideal de progresso social. Segundo Penna (1927 In: COSTA; SHENA; SHIMIDT, 1997, p. 30),

[...] mais de $90 \%$ dos brasileiros não sabem ou não têm suficientemente educadas a inteligência e a vontade para defender e melhorar incessantemente a própria vida, é evidente que não contribuem para a defesa e melhoramento da vida da família, da sociedade e da espécie. 
A industrialização e a modernização de acordo com a perspectiva fordista era uma realidade a ser alcançada no Brasil. Este surto industrial que reconfigurou as relações sociais a partir do final do século XIX foi impulsionado e influenciado pelos Estados Unidos. Outros países como a Alemanha e a Inglaterra também despontaram como grandes potências econômicas no cenário internacional. Sendo a eugenia supostamente a ciência responsável pelo aprimoramento do corpo social, atribuía-se ao sucesso econômico dessas nações o fator "raça", o que justificou a proliferação de sociedades e organizações eugênicas pelo mundo durante esse período. Os apologistas da eugenia compreendiam-na como sendo a ciência responsável pela manutenção e garantia do futuro da "raça" humana frente aos problemas de "degenerescência", tais como as doenças sexuais, os vícios e a miscigenação.

Por intermédio da educação é que se preveniria a degradação da espécie. O sujeito almejado deveria ser dotado de bons hábitos e de boa constituição física, atributos necessários para o exercício de atividades laborais e para procriação de "boas espécimes." O eugenista e zootecnista Octávio Domingues aderiu ao discurso vigente na época, partilhando do mesmo entendimento do professor e literato Coelho Neto (1937). Tanto Domingues quanto Coelho Neto viam na educação o principal instrumento necessário para a formação do novo indivíduo eugenizado. Nas palavras de Domingues (1929, p. 143): "Pela educação, podemos ensinar a todos os humanos a beleza das uniões eugênicas, e pregar o horror à reprodução entre os tipos cuja herança biológica claudicante for uma ameaça fatal à descendência”.

Para os eugenistas mais radicais, como Renato Kehl (1929, 1933), a "degenerescência" biossocial seria resultado de determinismos biológicos. Naquele contexto, o eugenista propôs em um de seus ensaios sobre engenharia social o modelo moral ideal a ser realizado na concepção de proles eugenizadas. Diante de valores morais e religiosos entendidos como limitadores da evolução e, por conseguinte, potenciais riscos à sobrevivência da espécie, o adultério não seria uma traição se cometido em nome da causa eugênica. A moral social tradicional era relativizada em nome do bem-estar do corpo social e da espécie, como ilustra esta historieta criada por Kehl, em que uma amiga de colégio sugere a outra que traia o marido “disgênico", porém rico, com o amante eugênico e pobre (1920, p. 179-180): 
Duas amigas de collegio, de boa família, conversam juntas. Uma suspira:

- O que tens? Pergunta a outra.

- Um grande pesar.

- Qual?

- Amo Roberto, e elle me ama.

- Maravilhosamente! Elle é bonito, jovem, elegante, é isto o que te afflige?

- Sim, mas elle é pobre, não tem nada, não é cousa alguma, e meus paes querem que eu me case com o barão, que é obeso, calvo, e feio, mas poderosamente rico.

- Pois bem! Minha tola, casa-te tranquillamente e faz com que elle se relacione com

Roberto.

Assim, para os eugenistas do começo do século XX, a questão da educação como potencializadora de um novo governo de si, capaz de regenerar o corpo coletivo da nação, era uma questão central. Para tanto, haveria a necessidade de se ampliar a oferta de matriculas no ensino. O que possibilitaria a reeducação do povo, incutindo desde a mais tenra idade uma consciência higiênica, eugênica e sanitária (PENNA, 1927 In: COSTA; SHENA; SHIMIDT, 1997).

Economicamente, a sociedade deveria ser preparada sobretudo para a atividade laboral. O aprimoramento do homem, ou seja, o fortalecimento (eugenização) do corpo físico seria orientado para esse fim (DOMINGUES, 1929). Contrapondo essa perspectiva radical professada por Kehl, em que a sobrevivência da espécie humana se daria somente por meio de pares eugenizados, o antropólogo brasileiro Roquette-Pinto $(1933,1936)$ entendia que os problemas do país seriam de ordem sociocultural e não biológica.

Em consonância com o movimento escolanovista, a universalização da escola seria então uma realidade a ser alcançada (AZEVEDO, 1958). Ainda assim, ampliar o acesso ao ensino não significaria necessariamente igualdade de oportunidades. O sentido "aristológico" de Ernesto Nelson privilegiou o biológico em detrimento ao caráter socioeconômico que antes pautava a seleção de alunos. Reconhecia-se “[...] a todo o indivíduo o direito a ser educado até onde o permitiam suas aptidões naturais, independente de razões de ordem econômica e social." (MANIFESTO DOS PIONEIROS, 1932, p. 40). Contudo, não se pode generalizar os discursos, pois assim como no campo da educação dentro do movimento Escola Nova brasileiro, as proposições teóricas sobre o modelo ideal de ensino a se instituir no país foram distintas e, por vezes, contraditórias.

O ensino deveria ser fragmentado de acordo com a idade dos educandos. Os alunos de 4 a 6 anos de idade frequentariam a educação infantil, dos 7 aos 12 anos, o ensino primário e dos 12 aos 18 o secundário. Para Azevedo (1958), cada etapa teria em si uma atribuição no processo formativo, que compreenderia uma formação cultural, moral e profissionalizante adequada às aptidões econômicas de cada região. Ademais, através de estudos alicerçados no 
campo da psicologia, dentre os quais do psicólogo francês Édouard Claparède (1973), fundamentou-se a concepção acerca das aptidões como algo inato e individual. A formação estaria relacionada às capacidades naturais e qualquer tipo de ensino que visasse desenvolver competências não-congênitas seria um desperdício de recursos. Em suas palavras: “[...] aptidão é uma disposição natural a comportar-se de certa maneira, a compreender ou sentir de preferência certas coisas ou a executar certas espécies de trabalho." (CLAPARÈDE, 1973, p. 167). Logo, seria como “[...] perder tempo, querer por força desenvolver nele capacidades não possuídas, [...] 'não se obriga a natureza, a não ser obedecendo-lhe.' Sim, é preciso obedecer a natureza da criança, se dela queremos fazer alguma coisa; é a condição sine qua non." (CLAPARÈDE, 1973, p. 174).

As metodologias ativas, propugnadas pelos reformadores escolanovistas, buscavam no aluno a centralidade do processo de ensino-aprendizagem, seguindo os modelos que nessa época proliferavam nos Estados Unidos e na Europa. Nesse sentido, o pedagogo estadunidense William Heard Kilpatrick (1978) atentou em seus estudos para a necessidade de o professor restringir sua ação ao auxílio no desenvolvimento discente. O docente deveria ter sua figura esmaecida frente ao ensino e ao currículo, que deveriam ser centrais na formação do indivíduo e no desenvolvimento de suas aptidões. Na atualidade, essa tendência de individualização tende a ser potencializada e levada ao extremo, cabendo ao educando a gerência e a responsabilização pelo seu itinerário formativo e seleção de conteúdos que irão compor o seu currículo.

A “[...] educação, no caso, a instituição escolar, é o espaço por excelência da circulação das verdades sobre o sujeito.” (SILVA, 2014, p. 903). Esses discursos viriam a definir os “[...] regimes de verdade que balizam e separam o verdadeiro do contrário." (VEIGA-NETO, 2014, p. 101). Ou seja, a constituição de determinados valores é difundida e assimilada socialmente por intermédio da educação, dentre os quais a meritocracia. Se no passado os fatores biológicos determinariam o acesso a diferentes níveis de ensino e, por conseguinte, à mobilidade social, no presente, o discurso meritocrático se manifesta por intermédio do fomento à gestão individualizada da própria vida segundo as necessidades e anseios próprios.

Na ótica neoliberal, a desfiliação da sociedade passa a ser atribuída às escolhas de vida, em que o insucesso não está mais relacionado à estrutura da sociedade e/ou à falta de oportunidades. O "neossujeito" é pensado como aquele que não necessita mais de tutela do Estado. Ele deve ser criativo, proativo e autônomo na busca de oportunidades disponíveis, no intuito de se tornar financeiramente independente, gerar renda e realizar seus próprios sonhos e desejos por meio de uma (auto) formação que possibilite o desenvolvimento de seus potenciais 
e aptidões. Desse modo, visa-se garantir a inserção social e a alocação do indivíduo no mundo do trabalho, o que será analisado na seção seguinte.

\section{Heterogeneidade biossocial, educação e políticas de autonomia e de responsabilização na perspectiva do neoliberalismo}

Desníveis culturais tendem a reverberar essas disparidades no campo social. Este tem sido o dilema da educação e da política: equiparar desigualdades socioculturais para ampliar o acesso e a permanência dos educandos no sistema (CALVINO, 2009). É nesse sentido que as políticas afirmativas contribuiriam para o acesso à educação de camadas sociais desfavorecidas historicamente. Expressões como "habilidades", "recrutamento" e "treinamento" denotam a íntima imbricação entre mercado e educação na nova semântica educacional, em que todos devem ser ativos, autônomos e geradores de renda na sociedade neoliberal.

Seguindo a orientação do mercado, durante o Governo de Fernando Henrique Cardoso, instituiu-se em 1996 a LDBEN. Com isso, no que se refere à educação, o objetivo do ensino público passou a contemplar, além da formação para a cidadania, o preparo para o mercado de trabalho.

\footnotetext{
Art. $1^{\circ}$ A educação abrange os processos formativos que se desenvolvem na vida familiar, na convivência humana, no trabalho, nas instituições de ensino e pesquisa, nos movimentos sociais e organizações da sociedade civil e nas manifestações culturais.

$\S 1^{\circ}$ Esta Lei disciplina a educação escolar, que se desenvolve, predominantemente, por meio do ensino, em instituições próprias.

$\S 2^{\circ}$ A educação escolar deverá vincular-se ao mundo do trabalho e à prática social. (BRASIL, 1996).
}

Conforme mencionado acima, essa tomada de posição pelo neoliberalismo expresso na LDBEN foi reforçada mediante a resolução $n^{\circ} 2$ de 2001, estabelecendo que: “[...] as escolas das redes de educação profissional podem avaliar e certificar competências laborais de pessoas com necessidades especiais não matriculadas em seus cursos, encaminhando-as, a partir desses procedimentos, para o mundo do trabalho.” (BRASIL, 2001).

A mudança de governo ocorrida a partir de 2003 seguiu a mesma linha formativa, em que se almejou a autonomia e a inclusão. Considera-se um indivíduo incapaz de prover a si próprio aquele que não contemplar ao menos duas das 8 habilidades definidas: “[...] comunicação; cuidado pessoal; habilidades sociais; utilização dos recursos da comunidade; saúde e segurança; habilidades acadêmicas; lazer; e trabalho; [...]” (BRASIL, 2004).

Através de orientações sociais impostas pelo mercado, foi desenvolvido o Programa Nacional de Inclusão de Jovens (PROJOVEM), cujo intuito era o de promover a geração de 
renda e, com isso, assegurar a inserção social do educando. Percebe-se que o foco das políticas educativas se centra no preparo para o mundo do trabalho. Essa posição fica clara ao analisar o Decreto $\mathrm{N}^{\circ} 6.629$ de 04 de novembro de 2008: "IV - preparar o jovem para o mundo do trabalho, em ocupações com vínculo empregatício ou em outras atividades produtivas geradoras de renda." (BRASIL, 2008).

Nesse processo, a pressão por resultados, mesmo sendo atribuída aos educandos, é compartilhada entre todos os atores envolvidos no processo de ensino-aprendizagem. De acordo com Sommer e Schmidt (2012, p. 11), os "Professores se cobram porque não conseguiram ensinar suficientemente seus alunos para atender as demandas da sociedade. A escola é pressionada pelas engrenagens do mercado para dar conta de tudo." A sensação de falha invariavelmente recai nas escolas e nos profissionais docentes, responsabilizados pela educação inadequada para com os discentes - resultados de políticas neoliberais de avaliação e de responsabilização.

Além do já existente Sistema de Avaliação da Educação Básica (SAEB), no ano de 2007 houve a instituição do Índice de Desenvolvimento da Educação Básica (IDEB), que tem sido um indicador usado pelo governo para atestar e verificar a qualidade de ensino das instituições escolares, o que se dá através de avaliações sistemáticas. A nota é mensurada de acordo com as etapas do ensino. Atualmente o país alcançou 5,8 para os anos iniciais ( $1^{\circ}$ ao $5^{\circ}$ ano) e média de 3,8 para o ensino médio. A meta é subir o índice Brasil para 6,0 até 2021, patamar estipulado como ideal de acordo com a Organização para a Cooperação e Desenvolvimento Econômico (OCDE). Conforme aponta Brooke (2006, p. 385), “[...] a utilização de um sistema nacional de avaliação extensiva a todas as escolas parecem indicar a vontade de exercer maior controle sobre as autoridades educacionais, a escola e o ensino."

O fomento à competição tem sido o principal objetivo dessas ações, fazendo com que os indivíduos internalizem a racionalidade neoliberal que deve reger o governo de si do neossujeito. O educando em processo de formação, ao final de seu ciclo, deverá ser dotado de capacidades autônomas como o "aprender a aprender" e a habilidade de aproveitar oportunidades e empreender em um mercado competitivo. Em seu estudo sobre a governamentalidade neoliberal, Gadelha (2009) demonstra como as pautas econômicas migram para outras áreas sociais, fazendo com que os indivíduos sejam subjetivados ao ponto de se tornarem todos microempresários de si. Conforme o professor Alfredo Veiga-Neto, esse ato de conduzir as condutas reverbera em uma ação de governamento, ou seja, autogoverno de si que se dá através de processos de subjetivação que são externos (leis, discursos etc.). Sobre as técnicas de governo, Veiga-Neto $(2005$, p. 82) define que o mais adequado é utilizarmos o 
termo "[...] governamento nos casos em que estiver sendo tratada a questão da ação ou ato de governar."

Não somente os sujeitos são capturados pela racionalidade neoliberal. Instituições como a escola também acabam sendo incorporadas a essa lógica. Isso ocorre devido às "micropráticas" que se fundamentam na competição entre indivíduos e na corrida para se aperfeiçoar e melhorar o próprio desempenho (BALL, 2010). Os “" [...] esforços adicionais de investimento - treinamentos, cursos, atualizações - para preservar seu valor e manter ou aumentar seus rendimentos" (LÓPES-RUIZ, 2007, p. 69) fomentam esse processo de autoempreendedorismo. O insucesso dos sujeitos antes atribuídos ao sistema escolar ou aos professores passa aos poucos a ser entendido como uma incompetência pessoal, incoerência de suas escolhas ao longo da vida.

De acordo com essa prerrogativa, Anderson (2010) entende que os resultados fundamentam as políticas educacionais, fazendo com que haja uma cultura de responsabilização que recaí sobre o aluno. A performatividade, a autenticidade e a gestão de sua existência têm por intuito a promoção da autonomia discente em seu processo formativo, bem como abandonar o educando à própria sorte de suas escolhas. Esse processo visa isentar o Estado e a sociedade frente ao possível fracasso do educando - “incapaz” de criar suas próprias oportunidades ou de se responsabilizar por suas próprias escolhas.

Denota-se que nas primeiras décadas do século XX, o discurso biológico apregoava que a existência de indivíduos "degenerados" causaria risco à sociedade, devido a sua constituição hereditária. Com isso, objetivava-se à homogeneidade biossocial. Nos dias atuais, a heterogeneidade biossocial torna-se o combustível do neoliberalismo, pois o ser humano ideal do século XXI é maleável e adaptável às demandas do mercado. A racionalidade neoliberal impõe a todos a necessidade de competir em um ambiente de risco, gerar renda e com isso garantir sua autonomia social - gerindo desse modo sua própria existência. A inserção no mundo do trabalho torna-se essencialmente meritocrática. A intervenção do Estado ou o estabelecimento de qualquer outra ação social neste processo privilegiaria supostamente alguns indivíduos em detrimento de outros, prejudicando o mecanismo da concorrência.

Nesse sentido, a hiperindividualização dos processos de aprendizagem visa promover uma diferenciação que se configura através da seleção dos conhecimentos a serem adquiridos e do próprio processo formativo. Esse método estaria alicerçado na estetização da vida e no capitalismo artista (LIPOVETSKY; SERROY, 2015), tornando os indivíduos únicos e autênticos. Conforme Drucker (1991), o “indivíduo instruído" se forma através da ação do professor que tem por objetivo identificar os pontos fortes do educando e, assim, guiá-lo de 
maneira não-arbitrária em seu processo formativo. O que corrobora os pressupostos da racionalidade neoliberal uma vez que “[...] a pessoa instruída é capaz de aprender permanentemente." (SILVA, 2018, p. 561).

Nessa perspectiva, o estímulo ao protagonismo juvenil e a flexibilização do currículo possibilitam aos jovens certa autonomia para definirem seus itinerários formativos. $\mathrm{O}$ que evidencia o avanço das políticas neoliberais no campo da educação. Conforme proposto pelo Ministério da Educação, a Reforma do Ensino Médio define que:

\begin{abstract}
Diferentemente do Ensino Fundamental, para o Ensino Médio não há indicação de anos na apresentação das habilidades, não só em função da natureza mais flexível do currículo para esse nível de ensino, mas também, como já referido, do grau de autonomia dos estudantes, que se supõe alcançado. Essa proposta não mais impõe restrições e necessidades de estabelecimento de sequências (que já são flexíveis no Ensino Fundamental), podendo cada rede de ensino e escola organizar localmente as sequências e simultaneidades, considerados os critérios gerais de organização apresentados depois de cada campo de atuação. (BRASIL, 2017, p. 493).
\end{abstract}

Sendo assim, o indivíduo que não busca o (auto) aprimoramento - o constante empreender-se - assume o risco de ser desfiliado da sociedade. A educação toma outro rumo: os alunos, concebidos como clientes, seriam meros consumidores que passam a comprar "competências" a fim de alocar-se no mercado de trabalho (BAUMAN, 2008). Diante disso, o que se contrapõe nesse rearranjo coletivo é o embate entre o fascismo social e o reconhecimento da diferença; a cidadania de uma parcela da sociedade passa a ser contestada por uma elite privilegiada e pelas classes médias, ciosas por manter seus privilégios tradicionais (SANTOS, 2010).

O fracasso individual estaria relacionado às escolhas de vida e não mais às desigualdades étnico-sociais e/ou biológicas. Se no passado a homogeneização da sociedade se daria através da igualdade "racial", atualmente a heterogeneidade biossocial passa a funcionar como um novo imperativo. Partindo da premissa de que não somos iguais biologicamente e de que há uma flexibilização das normas de comportamento, algo característico dos tempos neoliberais, a competitividade se pauta na atualização dos discursos biológicos para promover e naturalizar a diferenciação entre os indivíduos e difundir seus ideais.

Partindo desse pressuposto da heterogeneidade biológica, exclui-se, por exemplo, deste modo as adaptações que antes eram garantidas em lei para as pessoas com necessidades especiais em concursos públicos. Agora, o mesmo critério avaliativo confere-se e aplica-se a todos os participantes. Aos deficientes seguem permitidas o uso de tecnologias que os auxiliem no dia-a-dia; todavia, passam a ser vetadas adaptações adicionais durante o certame. O Decreto $n^{\circ}$ 9.546, de 30 de Outubro de 2018, “Altera o Decreto n 9.508, de 24 de setembro de 2018, 
para excluir a previsão de adaptação das provas físicas para candidatos com deficiência e estabelecer que os critérios de aprovação dessas provas poderão seguir os mesmos critérios aplicados aos demais candidatos." Ainda sobre o decreto,

\begin{abstract}
VI - a previsão da possibilidade de uso, nas provas físicas, de tecnologias assistivas que o candidato com deficiência já utilize, sem a necessidade de adaptações adicionais, inclusive durante o curso de formação, se houver, e no estágio probatório ou no período de experiência." (NR)

$\S 4^{\circ}$ Os critérios de aprovação nas provas físicas para os candidatos com deficiência, inclusive durante o curso de formação, se houver, e no estágio probatório ou no período de experiência, poderão ser os mesmos critérios aplicados aos demais candidatos, conforme previsto no edital." (NR). (BRASIL, 2018).
\end{abstract}

A influência da racionalidade neoliberal imbrica-se à atualização dos discursos biológicos para o planejamento de políticas sociais que se pautam na garantia da livre concorrência entre os indivíduos por meio da meritocracia. Ainda assim, as políticas afirmativas que visam à mobilidade física de deficientes permaneceriam uma vez que não causariam prejuízos à competitividade.

Os deficientes que no início do séc. XX eram entendidos como "indesejáveis", atualmente passam a ser "invisibilizados" socialmente, o que nas palavras de Bauman (1998, p. 84-85) é “" [...]apenas uma reencenação da mesma peça montada, embora, admita-se com diálogos um tanto atualizados." O regime neoliberal determina que os novos paradigmas tanto para a educação quanto para o construir-se cidadão independe da constituição física. Tornar-se membro da sociedade no presente estaria condicionado à capacidade de autonomia e de geração de renda destes indivíduos.

De acordo com Silveira (2013), as pessoas caracterizadas como "inúteis", "desvalidos", "inadaptáveis" ou "resíduos" estariam condicionadas à margem da sociedade. O que não se refere a sujeitos beneficiados pela assistência estatal e, sim, aos que estão aquém das políticas públicas. Mesmo gerando estatísticas, muitos sequer possuem registro de identidade. Nasceram, viveram e provavelmente, morrerão “[...] desfiliados da sociedade.” (CASTEL, 2005, p. 543). A racionalidade neoliberal, calcada na meritocracia, faz com que a presença desses sujeitos seja esmaecida ao ponto de naturalizar sua invisibilidade ou, até mesmo, de apagá-los da sociedade.

\title{
Considerações finais
}

Nas primeiras décadas do século XX, o discurso biológico foi pauta de debates que envolviam políticas socioeducativas. Isso ocorreu devido, entre outras coisas, à crescente urbanização brasileira que reconfigurava o cenário social à época. As autoridades públicas 
pretendiam forjar indivíduos aptos para o trabalho, o que compreenderia uma formação moral, física e cognitiva.

Se na virada do séc. XX o discurso biológico promovia a hierarquização humana com base em aptidões físicas e cognitivas, atualmente, a sociologia se apropriou da biologia na fundamentação de uma nova matriz discursiva que se fundamenta na racionalidade neoliberal. A exclusão já não ocorreria mais sob o viés biológico, porquanto há no presente a desfiliação social de indivíduos que por "sua própria incapacidade" acabariam excluindo-se do contrato social e desse modo ficando à margem da sociedade.

Esse discurso meritocrático associado às práticas de livre-mercado almeja validação socioeconômica no suposto "[...] intuito de se salvaguardar a competitividade e eliminar privilégios" (PIZOLATI, 2021, p. 193, grifos nossos), resultados esses de ações afirmativas de inclusão e acessibilidade aos bens-comuns (saúde, educação e emprego). Essas estratégias políticas configuram-se na promoção de cotas sociais, étnico-raciais e inclusão de deficientes e LGBTQIA+ (Lésbicas, Gays, Bissexuais, Transexuais, Travestis, Transgêneros, Queer, Intersexuais, Assexuais...).

Á vista disso, as mudanças no campo da educação fazem com que as relações de trabalho e as relações socias sejam reconfiguradas, estabelecendo um novo imperativo, conforme o qual a flexibilização passa a pautar o modo como cada indivíduo se percebe e se insere no mundo (HARDT; NEGRI, 2012). Nessa perspectiva, a inclusão assume outro aspecto, em que a inserção no mercado de trabalho e a geração de renda tornam-se sinônimos de cidadania.

A articulação entre o neoliberalismo e a educação se torna perceptível ao observamos as políticas educativas promovidas pelo estado brasileiro após 1996 - advento da LDBEN. Se no início do século XX, a preocupação das elites políticas e intelectuais circundava o interesse de salvaguardar a sobrevivência da espécie humana, no hodierno, através da racionalidade neoliberal, passou-se a preconizar a autopreservação do indivíduo. Nessa lógica, é através do fomento à flexibilidade, à responsabilização e à "aprendificação" que esses "neossujeitos" regidos pelo discurso meritocrático se constituem em aprendentes por toda a vida. Em síntese, “[...] o neossujeito busca fazer de si uma microempresa e o processo formativo na escola será apenas um elemento propulsor para que esses jovens se autogovernem e se constituam em aprendentes autônomos e singularizados.” (PIZOLATI, 2020, p. 522).

O “neossujeito" define-se pela “[...] articulação entre individualização e a responsabilização" (SILVA, 2017, p. 700), as quais se relacionam à mentalidade mercadológica que preside a formulação das políticas públicas atuais. O efeito desse processo é o estímulo à concorrência com os outros e consigo mesmos, cujo resultado é a formação de um indivíduo 
pela lógica da competitividade (BALL, 2016 In: COLLET; TORT, 2016). Com isso, passa-se a conceber a educação de modo utilitarista, fenômeno esse que é intensificado por meio do impacto das políticas neoliberais no campo educacional (LAVAL, 2016).

O mundo globalizado e globalizante no qual os indivíduos estão inseridos faz com que a competição se manifeste no campo da pessoalidade, em que superar a si próprio é a nova meta imposta pelo paradigma socioeconômico; do contrário, serão desfiliados da sociedade, mais precisamente, do jogo neoliberal. Eis então que a sobrevivência do espécime humano (séc. XXI) se sobrepôs em importância ao da própria espécie humana (séc. XX).

\section{Referências}

ALVES, Alexandre; PIZOLATI, Audrei Rodrigo da Conceição. EUGENIA, EDUCAÇÃO E SABER MÉDICO: O DISCURSO EUGÊNICO NA I CONFERÊNCIA NACIONAL DE EDUCAÇÃO (1927). História \& Ensino, Londrina, v. 25, n. 1, p. 427-451, jan./jun. 2019. DOI: http://dx.doi.org/10.5433/2238-3018.2019v25n1p427

ANDERSON, Gary. A reforma escolar como performance e espetáculo político. Educação e Realidade, Porto Alegre, v. 35, n. 2, p. 57-76, mai./ago. 2010. Disponível em: https://seer.ufrgs.br/educacaoerealidade/article/view/12883 Acesso em 28 dez. 2018.

AZEVEDO, Fernando de. A educação entre dois mundos: problemas perspectivas e orientações. Obras completas. V. XVI, São Paulo: melhoramentos, 1958. p. 59-81.

BALL, Stephen. Performatividades e fabricações na economia educacional: rumo a uma sociedade performativa. Educação e Realidade, Porto Alegre, v. 35, n. 2, p. 37-58, mai./ago. 2010. Disponível em: https://seer.ufrgs.br/educacaoerealidade/article/view/15865. Acesso em 07 dez. 2018.

BALL, Stephen. Gobernanza neoliberal y democracia patológica. In: COLLET, Jordi; TORT, Antoni. (orgs.). La gobernanza escolar democrática. Madrid: Morata, 2016, p. 23-40.

BAUMAN, Zygmunt. Modernidade e holocausto. Tradução: Marcus Penchel. Rio de Janeiro: Jorge Sahar, 1998.

BAUMAN, Zygmunt. Vida para consumo: a transformação das pessoas em mercadoria. Rio de Janeiro: Zahar, 2008.

BRASIL. LEI DE DIRETRIZES E BASES PARA A EDUCAÇÃO NACIONAL. 1996.

Disponível em: http://portal.mec.gov.br/seesp/arquivos/pdf/lei9394_ldbn1.pdf. Acesso em: 10 jun. 2018.

BRASIL. RESOLUÇÃO CNE/CEB $N^{\circ}$ 2, DE 11 DE SETEMBRO DE 2001. Institui Diretrizes Nacionais para a Educação Especial na Educação Básica. Disponível em:

http://portal.mec.gov.br/cne/arquivos/pdf/CEB0201.pdf. Acesso em 10 jun. 2018. 
BRASIL. DECRETO N 5.296 DE DEZEMBRO DE 2004. Disponível em: http://www2.camara.leg.br/legin/fed/decret/2004/decreto-5296-2-dezembro-2004-534980norma-pe.html. Acesso em: 10 jun. 2018.

BRASIL. DECRETO $N^{o}$ 6.629, DE 4 DE NOVEMBRO DE 2008. Disponível em: http://www2.camara.leg.br/legin/fed/decret/2008/decreto-6629-4-novembro-2008-583089norma-pe.html. Acesso em: 10 jun. 2018.

BRASIL. Base Nacional Curricular Comum. Educação é a Base. Brasília, MEC/CONSED/UNDIME, 2017. Disponível em: http://basenacionalcomum.mec.gov.br Acesso em 22 out. 2018.

BRASIL. DECRETO No 9.546, DE 30 DE OUTUBRO DE 2018. Disponível em: http://portal.imprensanacional.gov.br/materia//asset_publisher/Kujrw0TZC2Mb/content/id/47 987595/do1-2018-10-31-decreto-n-946-de-30-de-outubro-de-2018-47987442. Acesso em: 22 out. 2018.

BROOKE, Nigel. O FUTURO DAS POLÍTICAS DE RESPONSABILIZAÇÃO EDUCACIONAL NO BRASIL. Cadernos de Pesquisa, v. 36, n. 128, mai./ago. 2006. Disponível em: http://www.scielo.br/pdf/cp/v36n128/v36n128a06.pdf. Acesso em: 13 nov. 2018.

CASTEL, Robert. As metamorfoses da questão social: uma crônica do salário. Tradução de Iraci D. Poleti. 5. ed. Petrópolis, RJ: Vozes, 2005.

CALVINO, Ítalo. Assunto encerrado: discursos sobre a literatura e a sociedade. São Paulo: Companhia das Letras, 2009.

CLAPRÈDE, Édouard. A Escola Sob Medida. Rio de Janeiro: Fundo de Cultura, 1973.

COELHO NETO. Higyene e cultura physica. Educação Physica, Rio de Janeiro, $n^{\circ}$ 13, dez. 1937.

DOMINGUES, Octávio. A hereditariedade em face da educação. Bibliotheca de Educação. Vol. VI. São Paulo: Companhia Melhoramentos, 1929.

DRUCKER, Peter. As novas realidades. São Paulo: Pioneira, 1991.

FOUCAULT, Michel. Microfísica do Poder. Organização, introdução e revisão técnica de Renato Machado. 26. ed. São Paulo: Graal, 2013.

FOUCAULT, Michel. Du gouvernement des vivants (1979-1980). Paris: EHESS; Gallimard; Seuil, 2012.

GADELHA, Sylvio. Biopolítica, governamentalidade e educação: introdução e conexões, a partir de Michel Foucault. Belo Horizonte: Autêntica, 2009.

HARDT, Michael; NEGRI, Antônio. MULTIDÃO Guerra e democracia na era do Império. Tradução de Clóvis Marques. Revisão técnica de Giuseppe Cocco. 2. ed. Editora Record Rio de Janeiro - São Paulo, 2012. 
HOBSBAWM, Eric John. A era dos impérios, 1875-1914. 6. ed. Rio de Janeiro: Paz e Terra, 2001.

KEHL, Renato Ferraz. Eugenia e Medicina Social: Problemas da vida. Rio de Janeiro: Livraria Francisco Alves, 1920.

KEHL, Renato Ferraz. Lições de eugenia. Rio de Janeiro; Livraria Francisco Alves, 1929.

KEHL, Renato Ferraz. Aparas eugênicas: Sexo e Civilização. Rio de Janeiro: Francisco Alves, 1933.

KILPATRICK, William Heard. Educação para uma civilização em mudança. Tradução profa. Noemy S. Rudoulfer. - 16. ed. - São Paulo: Melhoramentos; [Rio de Janeiro]:

Fundação Nacional de Material Escolar, 1978.

LAVAL, Christian. Governar pela crise democrática [entrevista]. Revista cult, [UOL] n. 219, ano 19, p. 22-28, jun. 2016. Disponível em: https://revistacult.uol.com.br/home/governarpela-crise-democratica/. Acesso em 10 ago. 2018.

LIPOVETSKY, Gilles; SERROY, Jean. A estetização do mundo: viver na era do capitalismo artista. São Paulo: Companhia das Letras, 2015.

LÓPEZ-RUIZ, Osvaldo. Os executivos das transnacionais e o espírito do capitalismo: capital humano e empreendedorismo como valores sociais. Rio de Janeiro: Azougue Editora, 2007.

MANIFESTO DOS PIONEIROS DA EDUCAÇÃO NOVA. A reconstrução educacional no Brasil, 1932.

PIZOLATI, Audrei Rodrigo da Conceição; ALVES, Alexandre. Os debates sobre educação moral, conduta e caráter do indivíduo nas primeiras décadas do século XX e seus reflexos na atualidade. Revista Brasileira de Estudos Pedagógicos - RBEP/INEP. Brasília, v. 100, n. 256, p. 651-674, set./dez. 2019. DOI: https://doi.org/10.24109/2176-6681.rbep.100i256.4161.

PIZOLATI, Audrei Rodrigo da Conceição. A Influição do Discurso Neoliberal na Governamentalidade Pedagógica no Brasil Contemporâneo. Cocar, Belém, v. 14, n. 28, p. 521-540, jan./abr. 2020. Disponível em:

https://periodicos.uepa.br/index.php/cocar/article/view/3136. Acesso em: 23 ago. 2021.

PIZOLATI, Audrei Rodrigo da Conceição. Educação, trabalho e deficiência na I Conferência Nacional de Educação (1927). Caminhos da História, Montes Claros, v. 26, n. 2, p. 189-205, jul./dez. 2021. Disponível em:

https://www.periodicos.unimontes.br/index.php/caminhosdahistoria/article/view/4358/4404. Acesso em: 23 ago. 2021.

PENNA, Belisário. POR QUE SE IMPÕE A PRIMAZIA DA EDUCAÇÃO HIGIÊNICA ESCOLAR. In: COSTA, Maria José Ferreira Franco da; SHENA, Denílson Roberto; SHIMIDT, Maria Auxiliadora. I Conferência Nacional de Educação. Brasília MEC SEDIAE/INEP IPARDES, 1997. p.29-32. 
ROQUETTE-PINTO, Edgard. Ensaios de antropologia brasiliana. São Paulo: Cia. Editora Nacional, 1933 ("Biblioteca Pedagógica Brasileira", série V, Coleção "Brasiliana", vol. XXII).

ROQUETTE-PINTO, Edgard. Os fundamentos biológicos da sociologia. Jornal do Comércio. Rio de Janeiro: 25 mar., 1936.

SANTOS, Boaventura de Souza. A gramática do tempo: para uma nova cultura política. (coleção para um novo senso comum, v. 4). 3. ed. São Paulo: Cortez, 2010.

SILVA, Mozart Linhares da. Biopolítica, educação e eugenia no Brasil (1911-1945). Revista Ibero-Americana de estudos em educação. Araraquara, v. 8, n. 4, p. 900-922, out./dez. 2014. DOI: https://doi.org/10.21723/riaee.v8i4.5070

SILVA, Roberto Rafael Dias da. Emocionalização, algoritimizção e persoalizaçã dos itinerários formativos: como operam os dispositivos de customização curricular? Currículo sem Fronteiras, Porto Alegre, v. 17, n. 3, p. 699-717, set/dez. 2017. Disponível em: http://www.curriculosemfronteiras.org/vol17iss3articles/silva.pdf. Acesso em: 10 ago. 2018.

SILVA, Roberto Rafael Dias da. Estetização Pedagógica, Aprendizagens Ativas e Práticas Curriculares no Brasil. Educação \& Realidade, Porto Alegre, v. 43, n. 2, p. 551-568, abr/jun 2018. Disponível em: http://www.scielo.br/scielo.php?pid=S2175-

62362018000200551\&script=sci_abstract\&tlng=pt. Aceso em: 10 ago. 2018.

SILVEIRA, Alair Suzeti da. Estado do Bem-Estar Social e desfiliação social. Política \& Sociedade, Florianópolis, v. 12, n. 23, jan./abr. 2013. Disponível em:

https://periodicos.ufsc.br/index.php/politica/article/view/2175-7984.2013v12n24p145/25562. Acesso em: 23 ago. 2021.

SOMMER, Luis Henrique; SCHMIDT,

Saraí. CRIANÇAS E JOVENS DO ENSINO FUNDAMENTAL: DISCUTINDO AS

TENTAÇÕES DO DEUS CONSUMO. In: Educação no Brasil: o balanço de uma década. $33^{\circ}$ REUNIẪO ANUAL DA ASSOCIAÇÃO NACIONAL DE PÓSGRADUAÇÃO E PESQUISA EM EDUCAÇÃO - ANPEd, 33, 2010, Caxambu/MG. Anais... ANPEd, 2010. Disponível em:

http://33reuniao.anped.org.br/33encontro/app/webroot/files/file/Trabalhos\%20em\%20PDF/G T13-6672--Res.pdf. Acesso em: 26 ago. 2021.

SOUZA, Vanderlei Sebastião de. Política biológica como projeto, a eugenia negativa e a construção da nacionalidade na trajetória de Kehl. 1917/1932. 2006. 220 f. Dissertação (Mestrado em Ciências da Saúde) - Programa de Pós-Graduação em História das Ciências da Saúde da Casa de Oswaldo Cruz. Fiocruz, Rio de Janeiro, 2006. Disponível em: https://www.arca.fiocruz.br/handle/icict/6134. Acesso em: 23 ago. 2018.

STEPAN, Nancy Leys. A hora da Eugenia: raça, gênero e nação na América Latina. Rio de Janeiro: Editora Fiocruz, 2005.

TEIXEIRA, Anísio. Relatório da Inspetoria Geral do Ensino do Estado da Bahia, apresentado como Anuário do Ensino do Estado da Bahia. Salvador, 1925. Disponível em: http://www.fgv.br/cpdoc/acervo/arquivo-pessoal/AT/textual/relatorio-da-inspetoria-geral-do- 
ensino-do-estado-da-bahia-apresentado-como-anuario-do-ensino-do-estado-da-bahia-bahia. Acesso em: 16 jun. 2018.

TEPEDINO, Alexandre. Eugenia. Faculdade de Medicina do Rio de Janeiro, 1914.

VEIGA-NETO, Alfredo. Governo ou Governamento. Currículo sem Fronteiras, Porto Alegre, v. 5, n. 2, p.79-85, jul/dez 2005. Disponível em:

http://www.curriculosemfronteiras.org/vol5iss2articles/veiga-neto.pdf Acesso em: 08 set. 2018.

VEIGA-NETO, Alfredo. Foucault \& a Educação. 3. ed. 1 reimp. - Belo Horizonte: Autêntica Editora, 2014.

XAVIER, Lindolpho. NECESSIDADES DA PEDAGOGIA MODERNA. In: COSTA, Maria José Ferreira Franco da; SHENA, Denílson Roberto; SHIMIDT, Maria Auxiliadora. I CONFERÊNCIA NACIONAL DE EDUCAÇÃO. BRASÍLIA MEC SEDIAE/INEP IPARDES, 1997. p. 65-72. 